\title{
To Explore China's Future Choices of Fertility Policy According to South Korea's Experiences
}

\author{
Li Xue \\ Department of Public Administration University of Jilin finance and Economics, \\ Changchun, Jilin province, China, 130117 \\ (jingshunli2000@yahoo.com.cn)
}

\begin{abstract}
China and South Korea both belong to the East Asian countries, their regional culture and the historical background are similar, and both two countries have the same choice of policy, and both obtained outstanding achievements in population control. South Korea has entered the super population aging era. Facing the aging population and low fertility level, the South Korean government began to change the policy direction in the 1960 's, from birth control to encourage fertility. The formation of China's family planning policy is the result of a long historical process, and the current is still in constant adjustment and improvement process. This paper attempts to review the historical development process and the reasons of fertility policy, carries on the analysis and evaluation of policy effect, to explore suitable for China's more reasonable planning policy according to South Korean fertility policy experiences.

Index Terms - South Korea, experience, family planning policy, enlightenment
\end{abstract}

\section{I . Foreword}

Population problem restricts the development of a nation's economy, the use of social resources and distribution. Under the condition of limited bearing capacity of natural environment, populations have important influence on the development of economic and social change. One country need to develop population policies in different periods to promote the healthy and sustainable development of social economy. Since the founding of new China, our country carried out different fertility policy in different historical period, especially the strict family planning policy to control population growth has made significant achievements. The main population problems of our country now are still huge population base, population aging, the obvious contradiction between population and environment resources, etc . In view of our country will face from endowment, economic development, social and other aspects of the multiple pressure in the future, China's family planning policy should shift towards a more reasonable direction, and clearly realize the population long-term balanced development, alleviate the contradiction between the population resource, environment and economic development.

By contrast , South Korea's culture and historical background of the demographic transition are similar to China's, South Korea's experiences and lessons in the process of fertility policy adjustment has very good enlightenment and reference to China.

\section{II . Historical evolution and comparison of China and South Koreas' policy}

\section{A. In the early 1950s}

New China was founded in 1949, economic and cultural levels are backward, economic recovery and construction need a lot of labours. Although there are not clear population policies, the government's attitude toward fertility and population growth is basically a laissez faire. On April 20, 1950 , the national ministry of health and the military commission by the ministry of health jointly issued the "authority forces women cadres abortion restrictions method", the rules "to ensure life safety and next generation matrix, ban illegal abortion". In 1952, on the basis of the above regulations, the ministry of health made a universal oriented "interim measures for restrictions on birth control and abortion", this regulation for women cadres was promoted across the country soon.

During this period, South Korea did not begin on the population regulation and intervention policies, fertility policy at this stage is a blank period, the increase and decrease of the population took its course.

\section{B. In the mid - $1950 \mathrm{~s}$ and $60 \mathrm{~s}$}

In 1953, the first national census showed that there were about 600 million people in China, the pressure of population surging was in strong contrast to the backward economic situation at that time. Due to concerns about population burden was overweight, the ministry of health issued the measures for contraception and induced abortion. By March 1955 the central in the ministry of health about birth control problem of the party report on "birth control is related to the broad masses of people's life a major policy issue ." At this point, the laissez faire policy was turning to controlling population growth. In 1956 , the central unveiled the 1956-1957 national agricultural development compendiums (revised draft), the outline explicitly pointed out: "in addition to the ethnic minority areas, birth control should be promoted an popularized in some densely populated place, meanwhile, planned fertility should be advocated. From 1960 to 1969 , the government again realized that rapid population growth had great impact on China's

\footnotetext{
* This article is the research achievement of the project of National Education Department of Humanities and Social Sciences Research: "China's family-planning policy under the background of population aging", project number: 12 YJC 840022 .
} 
economic development and people's life, regained the family planning policy.

South Korea signed armistice agreement in 1953, the economy was still in a state of stagnation, but the speed of population growth is very fast, it is similar with China after the founding, and South Korea began to control the population quantity. In 1962 the South Korean government began to advocate family planning, and established the first "small family" family planning programs. Through guidance and proper auxiliary measures to encourage citizens to have fewer children, the goal is to 1970, average annual population growth rate dropped to $20 \%$.

\section{From $1970 \mathrm{~s}$ to the mid $-80 \mathrm{~s}$}

Into the 1970s, due to the rapid drop in mortality, the population in our country and new born population were both very large. In 1971 under the state council issued a report regarding the family planning work, the report put forward to in the fourth five-year plan period, the lower the natural population growth rate year by year. By 1973, our country has entered a "night, dilute, less" period, strictly control the child birth. To put the population control in order to achieve the 2000 targets within 1.2 billion, the family planning policy and strengthened the efforts, in 1978 after our country entered the stage of "one-child", put forward the "" late childbirth of marry at a mature age, and have fewer healthy birth policy, advocating a couple having only one child.

After entering into the 1980s, although South Korea family planning schemes encouraged bearing child, South Korean women's fertility rate dropped substantially, but due to the 1950s of the population has reached the age of fertility, so the government stepped up efforts to control the population further, strengthen the family planning, similar to China, also advocated a couple have a child.

\section{$D$. In the late $80 \mathrm{~s}$ until now}

Since the early 1980s radical policy makes the masses contradiction intensifies, policies were hard to push. China entered the stage of adjustment. In the 1990s, along with the establishment of market economy family planning work has entered a new stage of development. In 1991, the central committee of the communist party of China made some adjustment according to the national actual situation of the state council, to allow eligible couples maternity second child. After 2000 , the central proposed the stable low birth level policies of the state council. And the current total fertility policy is to advocate a pair of husband and wife that bears one child only.

During this period South Korea began to implement new population policy. South Korea has family tradition of son preference, in the early 1990s South Korea was born infant sex ratio imbalance, for South Korea turned to adjust sex ratio at birth, and promulgated a series of laws to protect women's legitimate rights and social status. In the late 1990s, the government continued to adjust the infant on the basis of sex ratio at birth to encourage birth. Through long-term family planning policy adjustment, South Korea's birth rate drops rapidly and has maintained a downward trend. 1996, considering the future of young labours force shortages may occur and preventing the newborn population continued to decline, the South Korean government cancelled the control population's family planning policy. In 2005 the government introduced a series of fertility policy, allowing people got married at the age of 30 have the second child, in the same year the South Korea government for national birth offers a variety of preferential policies for family planning of the third, four children to provide care. In 2008, South Korea began to implement "free fertility" policy.

\section{III - The analysis and evaluation of China and South Koreas' policy implementation effect}

It is visible from the fertility policy development history of both China and Korea, one child policy is not static, it must be adapt to the definite level of formulation and adjustment of economic and social development. The history background and the reasons of the birth policy of China and South Korea are quite similar in some stage, in order to control the population quantity are through the strict family planning stage, particularly in the 1970 s, the family planning policy both made remarkable achievements, both countries have maintained a low fertility level or downward trend.

\section{A. fertility policy implementation effect}

\section{1) Declining fertility, both low birth level}

At the beginning of the founding of new China, China's population increased fast, during this period China's total fertility rate has been high. After Chinese government began to implement the family planning policy, especially in the 1970s, "night, dilute, less" policy created the miracle of declining fertility in China in the first ten years. To the total birth rate fell to 2.24 in 1980 , over the same period, the birth rate and natural population growth rate is also a small decline. Due to the early 1980s, short-term expansion of fertility desire makes the fertility rate sharply increase. Then the government further carried on adjustment. in 1990, the total fertility rate is 2.31 , the birth rate is $20.98 \%$. Since then, China's one child policy has become stable and mature, the declining birth rate is stable, the birth rate of 19.7 per thousand in 1991 , fell to 14.0 per thousand in 2000 , 2009 , the total fertility rate is 1.6 , the fertility rate has dropped to 12.1 per thousand ${ }^{2}$.

South Korea began to carry out family planning policy since 1960s, the trend of excessively rapid growth of population contained, effectively control population quantity, population declining birth rate, the mid 80 South Korea's birth rate dropped to replacement level of 2.1. From 1980 to 1999, South Korea's total fertility rate dropped from 2.6 to 1.6 , has been falling ever since. But in the long run, the fertility rate continued to decline, or will make South Korea enter into the state of population growth. In 1996 South Korea began to shift policy direction, from the birth control to encourage birth, implementation of various preferential policies to encourage the national birth, but it is still difficult to reverse the trend of

\footnotetext{
${ }^{2}$ Guo Wiming. "South Korea's population control policy formulation and implementation"[J]. Population and family planning,1993,(6).
} 
falling birth rates. In 2009 South Korea's total fertility rate fell to 1.2 from 1.15 in 2008 , the birth rate dropped from 9.4 per thousand in 2008 to 9.4 per thousand ${ }^{3}$

\section{2) The population sex ratio imbalance, at the same time}

Both China and South Korea are traditionally with a preference for boys, the two countries during the family planning policy has appeared the status of sex ratio imbalance. Our population sex ratio at birth was 107.6 in 1981, the fourth census in 1990, the population sex ratio at birth in rose to 111.2 in 1989, has gone far beyond the normal range. Continue to rise to 119.9 in 2000, to 119.5 in 2009. During the period of family planning South Korea also inevitably appeared the population birth sex ratio imbalance problem. South Korea's sex ratio at birth was 103.9 in 1980. South Korea in 1980 the sex ratio at birth was 103.9. The 1988 survey found that $91.6 \%$ of the two-child family couples and $68.9 \%$ of the one-child couples who took contraceptive. However, only $79.8 \%$ percent of female head of households couples and $59.2 \%$ of female heads of household couple use contraception4. In 2010, South Korea's sex ratio at birth was 106.7, boys than girls5. South Korean population imbalance of sex ratio at birth has brought many trouble to the national in the marriage, economy, and from many aspects, such as medical care and education.

\section{3) The population ageing pension bring unprecedented pressure to retirement}

Since 1980s, the speed of China's population aging has been accelerated, the declining low birth level, increased the degree of population aging. In 2000 China's 65 - year - old or older, constituting proportion of the total population of $7 \%$ in 2012, according to the national economic and social development statistical bulletin, according to China's 65 - year - old or older population proportion of the total population of $9.4 \%$. Aging degree and the "empty nest" share will further increase. Fertility decline in China has contributed $27.11 \%$ of ageing population levels, and average life expectancy prolonged the contribution rate of $18.67 \% 6$. Rapid population aging has brought new problems and new challenges to social and economic development of our country, especially for the endowment problem.

South Korea's population aging process has a lot of similarities with China, which has completed the transition from traditional type to modern population, from 1960 to 1970 the proportion of elderly people in South Korea stayed in low level, the old accounted for the proportion of $3.1 \%$, since 1980 s this ratio began to rise, the in 1980 it increased to $3.8 \%$, rose to $5.1 \%$ in 1990 , according to south Korean reference, in 2000 ,South Korea's age 65 or older population reached

\footnotetext{
3 "South Korea development report 2011", Social Science Academic Press, 2011, 6, the first edition.

4 "Population and Family Planning."[J].1993, 6.

5 "South Korea development report 2011",Social Science Academic Press, 2011, 6, the first edition.

6 Yuan Xin, Liu Shijie. The population aging in China in 1982-2007 demographic factors analysis [J]. Journal of population,2007(5).
}

$7.1 \% 7$, South Korea has become a veritable population ageing country, and the rise of South Korea's first marriage age and sustained low fertility rates will make the condition even worse. In 2005, South Korea's total fertility rate fell to 1.1, the government have to pay more efforts to improve fertility, in response to the severe impact of population aging on pension security system.

\section{B. The evaluation of two countries' fertility policy effect}

The phase of the strict family planning policy focused on the number of control, the population quality, population structure and population distribution were not given the attention they deserve. Then the "one-child" policy did not follow the rules of population development. Considering the national affordability, the later policy that "to drive up small vent, but block the big" has obtained a better effect, it made China's population grew at a lower level. Family planning policy implemented so far, many negative effect have appeared. Such as the population aging, low fertility intention, and excessively high population sex ratio.

South Korea's encouraging policy on birth control is unfair in some ways. South Korea for pregnant women with fertility assistance policy only for formal employees, temporary workers and full-time housewife is not fair treatment accordingly. If encouraging birth policy wants to make effective progresses, it must find all aspects of reason for the declining fertility rate of and implementation of corresponding policies and measures. The reasons mainly include the junior class of economic problems, employment and family education expense burden and pressure, and other factors affecting the whole country's fertility intentions, etc.

\section{The enlightenment of South Korea's experience on China's family planning policy adjustment}

In period of family planning, China and South Korea has achieved the same positive effect on population control, but also caused the current between the two countries have to face the negative effects. The south's encourage birth policy to our country current if applicable, specific analysis according to the situation in China, even if let go of the fertility in China should consider what are the problems, these problems after the open policy will produce what kind of consequences, whether there is a corresponding solution to these problems, in this sense, the south Korean policy of our country has important reference value for the current fertility policy adjustment.

\section{A Positive response to population aging and labor shortages, fertility policy adjustment}

Along with the continuous decline in birth rate, and the resulting labor shortage and population ageing, in 1990s South Korea carried out a new population policy, the new policy cancelled the family planning policy, control population growth in turn encourage birth policy, improving national quality, improve the national welfare. China and Korea belong

\footnotetext{
7 Jin Duwan, Zheng Zhenzhen. South Korea's population aging process and its enlightenment[J].Journal of Population. 2007,(5).
} 
to the population aging countries. In addition, China's working-age population decline, in 2012, our country 15 to 59 years old (including under 60 years old) labor age population of 937.27 million people, 2012 fewer people than at the end of 2012 , accounting for $69.2 \%$ of the total population, $0.60 \%$ lower than at the end of 2012. Demographic dividend period in a shortened, the future labor shortage can be predictable; onechild couples have to bear the risk and pressure the emergence of these problems are with the family planning policy implemented in China since the latent negative effects have important relation, fertility policy adjustment, not only can relieve urban and rural aging process, and conducive to balance the population sex ratio at birth, at the same time to optimize the structure of family and satisfy people's childbearing.

\section{B. High cost of raising children, birth will drop significantly}

South Korea canceled the one-child policy and continuously encouraged birth, but the birth rate has not gone up, nor there a compensatory baby boom. South Korea's experience shows that, with the speeding up of urbanization process and the improvement of marriage age, the fertility rate would probably have been low. According to American economist Ben stein's research, with the increase of economic development and household income regardless of the cost of raising a child is as incomes rise and increase or decrease, or remain the same, parents to the child's needs will be reduced, to lower fertility rates.

\section{To improve women's status and restrain the imbalance sex ratio at birth}

According to South Korea's Institute of Health and Social Survey in 2005, the marriage professional experience fault ratio of spouse female (under the age of 45 ) was $60.6 \%$, while the career fault ratio after reproductive was up to $41.2 \%$. Even if the employment of women again obtain employment when their children grow up, it is difficult to find jobs with original income levels. This will increase the economic pressure to the families with dependent children, and also let a female to produce choose to avoid marriage family psychologically. In the aspect of improving women's status in our country also needs to be more perfect, publish relevant laws to maintain women's status, to eliminate discrimination against women in the work, all are beneficial to adjust the population sex ratio imbalance.

\section{The family planning policy adjustment should focus on rural areas}

China is a big agricultural country, which also has a big number of rural population, social and economic development has important influence on our country. The phenomenon of an aging population inversion between urban and rural areas has come up. So the family planning policy in China should focus on the rural areas. Our country can use for reference the experience of South Korea, after finishing the rural population demographic transition, the birth rate to replacement level, flexible policy of family planning should be taken to make the population birth rate still lingered in the replacement level. When the birth rate is higher than replacement level, strictly limit population growth, on the other hand, appropriate relax birth policy, to avoid the birth rate is too high or too low.

\section{Conclusion}

The large population and the rapid arrival of population aging have a huge pressure and significant impact on China's economic and social sustainable development. Whether birth control policies are reasonably effective become the important link to solve the problem of population in our country. Population fertility policy adjustment is an extremely complicated project, the problem should be considered from multiple angles, perfecting the policy, to make the right decisions, to create a good economic and social environment for the sustainable development. Facing the current situation and pressure, and the facts of our country has entered the low birth level, fertility policy adjustment is imperative. In the long run, let go of the urban and rural areas two births, strict control of a third child policy can alleviate the degree of population aging in our country, also a moderate and reasonable policy choice at present. In addition, the related supporting policies and measures also should be strengthened, such as efforts to increase urban and rural social security system construction, to improve population quality, to provide employment for women of childbearing age, to strengthen the propaganda education of one child policy in the new period, etc.

\section{References}

[1] Tian Xueyuan. China's demographic dividend has disappeared? People's Daily, 2013-01-25 (7).

[2] Yang Juhua. some about China's one child policy and fertility . Journal of Nanjing Population Management Cadre Institute., 2011 (2).

[3] Yao Xingyun; FuShaoPing. South Korea's policy and its enlightenment to China's rural population policy . Journal of northwest population, 2009. (2).

[4] Wang Guangzhou. Structure and future development trend of China's one-child total estimation . Research. Population, 2009 (1).

[5] Reference. Journal of China's low fertility level and its influencing factors. Population Studies, 2008 (4) b.

[6] Song Xiaowu, Jin Dongzhu. Comparative study of public policy to China and South Korea . Red flag publishing house. 2007.

[7] Qiao Xiaochun, Ren Jiang. China's future policy choices . Market Analysis and Population, 2006.

[8] Zhang Yi. Population control policy of historical change and the reform tendency. Journal of Guangzhou University. 2006 (8).

[9] Li Meihua. South Korea's population structure change on the influence of the social and economic development and the countermeasure research. 2006.

[10]Sun Muyu . History of China's family planning . Changchun . The Women's and Children's Publishing House, 1990 